SECTION I

\title{
Introduction
}





\section{CHAPTER ।}

\section{A Guide for the Perplexed}

\section{Thomas F. Babor, Kerstin Stenius and Jean O’Reilly}

"I do not presume to think that this treatise settles every doubt in the minds of those who understand it, but I maintain that it settles the greater part of their difficulties."

Maimonides, Guide for the Perplexed (ca. 1190)

To be perplexed is to be puzzled or even confused by the intricacy of a situation. One way to deal with perplexing situations is to find a guide who can provide advice, information, and direction. Many such guides have risen to the occasion throughout the ages, providing useful knowledge for the perplexed students of literature, religion, philosophy, and science. One of the most influential philosophical treatises, for example, was Maimonides' Guide for the Perplexed. In a time of religious, moral, and political change, Maimonides (1135-1204) sought to harmonize Greco-Roman, Christian, Jewish, and Arabic thought into a philosophical guide for those seeking meaning in life. In a sense, Publishing Addiction Science is intended to be a similar (albeit less ambitious!) guide for those of us who from time to time are perplexed about how to find our way through the complex world of addiction science. The chapters in this book constitute a virtual guide through the practical, scientific, moral, and even philosophical issues with which we must become acquainted if we are to succeed, either as temporary visitors to the field or as career scientists dedicating our lives to the study of addiction.

It is our contention - and a guiding theme of the book-that the key to successful publishing in addiction science is to understand not only how to write a scientific article and where to publish it but also how to do these things honestly and ethically. Therefore, in addition to the practical business of publishing

\section{How to cite this book chapter:}

Babor, T F, Stenius, K and O’Reilly, J. 2017. A Guide for the Perplexed. In: Babor, T F, Stenius, K, Pates, R, Miovský, M, O’Reilly, J and Candon, P. (eds.) Publishing Addiction Science: A Guide for the Perplexed, Pp. 3-8. London: Ubiquity Press. DOI: https://doi.org/10.5334/bbd.a. License: CC-BY 4.0. 
scientific articles in both multi-disciplinary and addiction specialty journals, the ultimate goal of this book is to enhance scientific integrity in the publication process, giving special consideration to the main organ of scientific communication, the scholarly journal.

\section{What is a Journal?}

According to Lafollette (1992, p. 69), “a journal is a periodical that an identifiable intellectual community regards as a primary channel for communication of knowledge in its field and as one of the arbitrators of the authenticity or legitimacy of that knowledge." Journals establish intellectual standards, provide a forum of communication among scientists, bring valuable information to the public, set the agenda for a field of study, provide an historical record of a particular area of knowledge, and confer implicit certification on authors for the authenticity and originality of their work (Lafollette, 1992). In addition, journals have the potential to serve the interests of career advancement and personal reward for scholarly achievement.

Journals are joint enterprises typically managed through a division of labor among owners, publishers, editors, reviewers, and authors. How this cast of characters is organized into an integrated set of players varies from one journal to another. The owners of a journal can be nonprofit organizations (such as learned societies, universities, or professional organizations), government agencies, or private publishers. The publishers of a journal range from small printers to large-scale, multi-national organizations that distribute often hundreds of journals. Journal editors tend to be appointed by the owners, society officers, or publishers. Editors of some of the larger scientific and medical journals are paid for their services and have full-time staff at their disposal. Editors of smaller journals are generally unpaid and have a small editorial staff with some volunteer assistant editors. Reviewers are usually established investigators who have specialized knowledge of the subject matter. Without remuneration and as a service to the field, reviewers provide critical and often anonymous evaluations of manuscripts written by their peers.

Without journals, addiction science-or any science-would have a limited audience and a short half-life. Therefore, scientists who wish to search for truth and to help humankind must understand the inner workings and current complexities of the journal publication process.

\section{Purpose of the Guide}

The addiction field has grown tremendously in the past 35 years, and addiction publishing has been no exception. Currently there are more than 120 journals devoted primarily to the dissemination of scholarly information about 
addiction and related health problems, and many more journals publish addiction science as part of their broader mission. Despite the growing amount of published material in addiction science and the increasing opportunities for publication, there exists no other guide designed to inform prospective authors about the opportunities, requirements, and challenges of publishing addiction science. Moreover, the addiction field has become perhaps one of the first areas of science in which interdisciplinary collaboration between biomedical and psychosocial researchers is essential to progress (see Edwards, 2002). At the same time, however, as Matilda Hellman (2015) argues, we appear to be moving into an age of academic compartmentalization, with increasingly narrow fields of study in which researchers are encouraged to specialize. It is therefore important that addiction science, a field that is perhaps unfashionably collaborative, has a publishing guide that looks at the field as an inter-related whole rather than as a collection of separate disciplines.

Within this context, the primary purpose of Publishing Addiction Science is to advise potential authors of articles in the addiction field of the opportunities for publishing their work in scholarly journals, with an emphasis on addiction specialty journals. Although all prospective authors will find such a guide useful, it should be particularly helpful to students, younger investigators, clinicians, and professional researchers.

The book's broader purpose is to improve the quality of scientific publishing in the addiction field by educating authors about the kinds of ethical and professional issues with which the International Society of Addiction Journal Editors (ISAJE) has long been concerned: scientific misconduct, ethical decision making, the publication process, and the difficulties experienced by authors whose first language is not English.

\section{Guide to the Guide}

Publishing Addiction Science is organized into five sections. The first section provides an overview of this book and a chapter ("Infrastructure and Career Opportunities in Addiction Science") describing the development and underlying structure of the field of addiction science.

The second section covers general issues of how and where to publish. The initial overview chapter (Chapter 3, "How to Choose a Journal: Scientific and Practical Considerations") deals with choosing where to submit your article, a very important decision in the publication process. The chapter describes the range of journals that publish articles related to addiction and psychoactive substances; summarizes the growth in addiction journals, including the move into open-access journals; and explains 10 steps to choosing a journal. It also provides two tables containing practical information about 45 addiction specialty journals (e.g., areas of interest, acceptance rates, author fees) to assist authors with the selection of an appropriate journal. The next chapter in this 
section ("Beyond the Anglo-American World: Advice for Researchers from Developing and Non-English-speaking Countries") describes the practical and professional issues addiction scientists face in countries that are less resourced or in which English is not the main language, how authors who come from these countries can improve their chances of publishing in English-language journals, the possibilities for authors to publish in both English and an additional language so they can communicate with different audiences, and how to decide whether an article may better serve the public by being published in the author's mother tongue. Chapter 5 (“Getting Started: Publication Issues for Graduate Students, Postdoctoral Fellows, and other Aspiring Addiction Scientists") describes the challenges and rewards of publishing early in one's professional career, including authorship issues, timetables, ethical dilemmas, and the pressure to publish. Lastly, Chapter 6 ("Addiction Science for Professionals Working in Clinical Settings") looks at research and publication issues specific to clinicians who work in the field of addiction. It offers advice for identifying types of clinical research that lend themselves to research articles, planning and funding such research, and avoiding common pitfalls in the journey to publication.

The third section provides a detailed guide to the practical side of addiction publishing. Chapter 7 ("How to Write a Scientific Research Article for a Peer-reviewed Journal") describes the development of a typical data-based research article from the planning stage to the completion of the final draft, emphasizing scientific writing techniques, the structure of a scientific article, common reporting guidelines for specific types of articles, effective methods of scientific communication, and resources for improving one's writing. The following chapter ("How to Write Publishable Qualitative Research") explores the differences and commonalities between qualitative and quantitative research, identifies the hallmarks of exemplary qualitative research, and offers practical advice not only for writing a qualitative article but also for getting it published. Chapter 9 ("How to Write a Systematic Review Article and Meta-analysis") provides a step-by-step process for designing, researching, and writing a comprehensive synthesis of existing research-typically a much larger undertaking than a single research article-and describes some of the best databases and guidelines available to authors. Chapter 10 ("Use and Abuse of Citations") describes appropriate and less-appropriate citation practices with recommendations for good behavior and gives a critical appraisal of citation metrics, particularly the journal impact factor, which is used to evaluate the importance attributed to different journals. Chapter 11 ("Coin of the Realm: Practical Procedures for Determining Authorship") deals with the often vexing question of how to assign authorship credits in multi-authored articles. We offer practical recommendations to provide collaborating authors with a process that is open, fair, and ethical. Chapter 12 ("Preparing Manuscripts and Responding to Reviewers' Reports: Inside the Editorial Black Box") focuses on how to negotiate the peer-review process. It describes how the process works and how 
journal editors make decisions about publishing an article. It also considers editors' criteria for selecting articles and explains how to revise an article when an editor asks for a response to the reviewers' comments. The final chapter in this section ("Reviewing Manuscripts for Scientific Journals") covers the peerreview process, what journal editors expect from reviewers, and how to prepare a constructive critical review.

The fourth section of Publishing Addiction Science is devoted to ethical issues. The first article in this section (Chapter 14, "Dante's Inferno: Seven Deadly Sins in Scientific Publishing and How to Avoid Them") reviews seven types of scientific misconduct in the context of a broader definition of scientific integrity. The seven "sins" are carelessness in citing and reviewing the literature, redundant publication, unfair authorship, failure to declare a conflict of interest, failure to conform to minimal standards of protection for animal or human subjects, plagiarism, and scientific fraud. We discuss these ethical improprieties in terms of their relative importance and possible consequences and suggest procedures for avoiding them. Chapter 15 ("The Road to Paradise: Moral Reasoning in Addiction Publishing") discusses the same issues in the context of a framework for making ethical decisions. We use case studies to illustrate the seven ethical topics, with a commentary on each case that demonstrates a practical approach to making sound decisions. Chapter 16 ("Relationships with the Alcoholic Beverage Industry, Pharmaceutical Companies, and Other Funding Agencies: Holy Grail or Poisoned Chalice?") reviews recent trends in the funding of addiction research and the ethical risks involved in accepting funding from industry as well as nonindustry sources.

The fifth and final section contains the book's concluding chapter (Chapter 17: "Addiction Publishing and the Meaning of [Scientific] Life"), in which the editors describe the pursuit of scientific integrity as a journey worth taking, as much for the joy of honest discovery as for the achievement of fame and fortune.

\section{How to Use This Guide Effectively}

The authors have collectively striven to present practical advice as well as "best practices." In most cases, such as in resolving authorship disputes or ethical problems, the solutions are not always simple or obvious but rather depend on the situation and on an open dialogue among colleagues. For these cases, we offer advice on how to use effective problem-solving techniques that will allow the reader to develop skills that can be applied to a variety of situations. The authors emphasize that no researcher, no matter how experienced in the game of science, can argue that she or he has all the right answers. This book is best seen as providing a basis for discussions about concrete problems in various research environments.

Although the book's chapters can be read in sequence, each chapter also functions as a self-contained unit and can be downloaded and read separately. 
As a result, there is some repetition among chapters, more so that would occur in a book designed to be read from cover to cover, as more than one chapter may discuss similar issues in slightly different ways.

The chapters are also meant for use as background readings for lectures, workshops, and practical exercises that accompany many of the chapters. The ISAJE website (www.isaje.net) contains supplementary readings, exercises, slides, and other materials for each chapter, all free to download.

Recognizing that there are important institutional responsibilities in the ethical conduct of addiction research, we hope that this book will also inspire research institutions to develop guidelines and policies that support the ethical practices considered in these chapters. Although we have subtitled the book as A Guide for the Perplexed, we point out that its chapters will be helpful as well to those who believe they have all the answers, including established investigators at professional organizations and scientific institutions.

Please visit the website of the International Society of Addiction Journal Editors (ISAJE) at www.isaje.net to access supplementary materials related to this chapter. Materials include additional reading, exercises, examples, PowerPoint presentations, videos, and e-learning lessons.

\section{References}

Edwards, G. (Ed.). (2002). Addiction: Evolution of a specialist field. Oxford, UK: Blackwell Publishing.

Hellman, M. (2015). The compartmentalisation of social science: What are the implications? Nordic Studies on Alcohol and Drugs, 32, 343-346.

Lafollette, M. C. (1992). Stealing into print: Fraud, plagiarism and misconduct in scientific publishing. Berkeley CA: University of California Press.

Maimonides, M. (2004). The Guide for the Perplexed. Translated by M. Friedländer [1903] (Barnes \& Noble Library of Essential Reading) Paperback. 